\title{
Aportes da teoria marxista da dependência para a análise da agropecuária e da indústria da mineração
}

\section{Gil Felix}

Universidade Federal da Integração Latino-Americana

Instituto Latino-americano de Economia, Sociedade e Política

Parque Tecnológico Itaipu, Av. Tancredo Neves, 6731 - Bloco 06

ILAESP - Conjunto B - 85867970

Foz do Iguaçu, PR

Brasil

Tel: +55 (45) 35292863

gilfelix@protonmail.com

https://orcid.org/0000-0001-8371-1358

\section{Resumo:}

Na Amazônia brasileira, a expansão das atividades da grande indústria da mineração tem mobilizado contingentes populacionais significativos para algumas cidades e tem sido anunciada como promotora do denominado desenvolvimento local, na medida em que superaria determinadas dinâmicas sociais presentes nas atividades antes economicamente predominantes. Neste sentido, baseado no que Ruy Mauro Marini planteou como teoria marxista da dependência, analiso os processos históricos de desenvolvimento das frentes de expansão na chamada Amazônia Oriental enquanto expressão de um processo histórico mais amplo de reprodução da dependência e da superexploração do trabalho. A investigação foi realizada com base em dados de pesquisa bibliográfica, pesquisa em arquivos de movimentos sociais e uma etapa de pesquisa e trabalho de campo, realizado em 2012, considerando uma investigação mais ampla desenvolvida pelo autor e iniciada em 2005 na mesma região.

Palavras-chave: Mineração; frentes de expansão; superexploração do trabalho; Ruy Mauro Marini; Amazônia. 


\section{Aportes de la teoría marxista de la dependencia para el análisis de las empresas agrícolas y de la industria minera}

\section{Resumen:}

En la Amazonía brasileña, la expansión de las actividades de la gran minería ha movilizado importantes contingentes poblacionales para algunas ciudades y se ha anunciado como impulsora del llamado desarrollo local, en la medida en que superaría determinadas dinámicas sociales presentes en las actividades previamente predominantes económicamente. En este sentido, a partir de lo que planteó Ruy Mauro Marini como una teoría marxista de la dependencia, analizo los procesos históricos de desarrollo de los frentes de expansión en la llamada Amazonía Oriental como expresión de un proceso histórico más amplio de reproducción de la dependencia y de la superexplotación del trabajo. La investigación se realizó a partir de datos de investigación bibliográfica, investigación en archivos de movimientos sociales y una etapa de investigación y trabajo de campo, realizada en 2012, considerando una investigación más amplia desarrollada por el autor e iniciada en 2005 en la misma región.

Palabras Ilave: Minería; frentes de expansión; superexplotación del trabajo; Ruy Mauro Marini; Amazonia.

\section{Contributions of the Marxist theory of dependency for the analysis of agricultural companies and the mining industry}

In the Brazilian Amazon, the expansion of large-scale mining activities has mobilized significant population contingents for some cities and has been announced as a driver of so-called local development, to the extent that it would overcome certain social dynamics present in previously economically predominant activities. In this sense, based on what Ruy Mauro Marini proposed as a Marxist theory of dependency, I analyze the historical processes of development of the expansion fronts in the so-called Eastern Amazon as an expression of a broader historical process of reproduction of dependency and super-exploitation of labour. The research was carried out based on bibliographic research data, research in archives of social movements and a stage of research and field work, carried out in 2012, considering a broader research developed by the author and started in 2005 in the same region.

Keywords: Mining; expansion fronts; super-exploitation; Ruy Mauro Marini; Amazon. 


\section{Aportes da teoria marxista da dependência para a análise da agropecuária e da indústria da mineração1}

Gil Felix ${ }^{2}$

\section{Introdução ${ }^{3}$}

Na Amazônia brasileira, particularmente a partir dos anos 1960, frentes de expansão agropecuária condicionaram formas específicas de mobilização e imobilização da força de trabalho, bem como processos violentos de expropriação de terras ocupadas por pequenos produtores, fatos esses que, na maioria das vezes, foram tomados como expressões do atraso e qualificados como maneiras arcaicas de expropriação e de superexploração que teriam lugar nos rincões atrasados do país e que, portanto, seriam substituídos e/ou superados pelo desenvolvimento econômico e social ou por uma intervenção estatal qualificada.

Neste sentido, baseado na denominada teoria marxista da dependência (Marini, 1973; 1973a; 1974; 1979; 1996; Felix, 2018; 2019; 2019a; 2020; s/d; Felix e Guanais, 2019; Felix e Sotelo Valencia, 2019), analiso processos históricos de desenvolvimento das frentes de expansão na chamada Amazônia Oriental brasileira enquanto expressão de um processo histórico mais amplo de reprodução da dependência e da superexploração do trabalho. Em seguida, abordo algumas implicações teóricas que tais processos representam para as interpretações que consideram as relações de superexploração do trabalho como expressões extemporâneas e superáveis através da promoção do que se denomina vagamente como desenvolvimento do capitalismo.

Nossa noção de dependência, para os fins desse artigo, tem referência na que sintetiza Ruy Mauro Marini em Dialectica de la dependencia e demais textos publicados por ele no mesmo período $(1973 ; 1973 a)$, como “(...) uma relação de subordinação entre nações formalmente independentes, em cujo marco as relações de produção das nações subordinadas são modificadas ou recriadas para assegurar a reprodução ampliada da dependência" (Marini, 1973: 3). No caso, dadas as devidas mediações, cabe frisar ao leitor/a também a análise da acumulação e do ciclo do capital na economia dependente, assim como a referência que grifamos em recente análise a respeito da importância do exército de reserva em tal esquema teórico e das dinâmicas de separação das esferas de produção, circulação e de realização dos bens consumidos pelos

\footnotetext{
1 O autor declara não haver conflito de interesses que poderia se constituir em um impedimento para a publicação deste artigo.

2 Professor da Universidade Federal da Integração Latino-americana. Autor, dentre outros, de: "O caminho do mundo: mobilidade espacial e condição camponesa em uma região da Amazônia Oriental", "Mobilidade e superexploração do trabalho: o enigma da circulação" e "Super-circulation: towards a political economy of platformisation".

3 O artigo faz uso de dados de pesquisa apoiada pela Fundação de Amparo à Pesquisa do Estado de São Paulo (FAPESP).
} 
trabalhadores (Marini, 1979; Felix, 2019). Aqui, em diálogo, ressaltamos alguns fatos que embasariam essa análise teórica face aos desdobramentos e encadeamentos internos de um processo histórico concreto, com especial atenção para a Amazônia brasileira contemporânea 4 .

\section{Frentes de expansão e superexploração do trabalho}

Feita a posteriori, uma análise da reprodução da dependência é bastante evidente no caso da Amazônia, particularmente no período recente. Afinal, como se verifica atualmente, especialmente após os últimos 50 anos, a implantação dos grandes projetos terminou por constituir uma região integrada de forma dependente ao mercado mundial como lócus para a produção de minérios, especialmente ferro, e, na última década, também para a produção de carne a partir de uma cadeia de produção com o capital concentrado em uma ou duas grandes empresas voltadas para exportação, cujos fornecedores, aos quais os pequenos produtores estão subordinados, são grandes e médias empresas agropecuárias. Nesse caso, portanto, é necessário um esboço de análise mais rigorosa, processual, cujos dados, por exemplo, não nos permitem creditar a reprodução da dependência apenas a partir do advento dos grandes projetos dos anos 1970.

Em 1972, Otávio Velho, pesquisador pioneiro das pesquisas realizadas diretamente na região, anunciava um "terceiro tempo" das frentes de expansão que alcançavam o sul e sudeste do estado do Pará. Esse seria bastante diferente das ocupações anteriores, exemplificadas por ele em uma pesquisa de campo em São Domingos, uma localidade camponesa formada a partir da frente de expansão agrícola que vinha do Maranhão (nordeste do Brasil), relativamente isolada, e, por outro lado, pela rápida alteração provocada pela construção da estrada PA-70 (atual BR-222), o ramal de Marabá à Belém-Brasília, que, em 1969, foi a primeira ligação rodoviária da região com os centros e demais mercados do país. O ramal de Marabá e, logo em seguida, a Rodovia Transamazônica representaram a chegada de agentes que alteraram profundamente a paisagem social, como era o caso dos pecuaristas. Nada comparável, porém, com o que se avizinhava a partir do anúncio do chamado novo tempo que acompanharia a construção das estradas, na época ainda em um tom especulativo. O próprio autor se viu obrigado a inserir mais um capítulo sobre essa questão, antes de publicar o livro, no qual sistematizava o seguinte:

São Domingos e a PA-70 representam exemplos de dois tempos diferentes na sobredeterminação local de forças produtivas geradas no âmbito de sistemas envolventes, que transformam o quadro da

\footnotetext{
4 Tal como referido a seguir, a seu tempo, o arcabouço teórico indicado foi constituído no meio intelectual vinculado à esquerda revolucionária latino-americana dos anos 1960 e 1970 e, nesse sentido, aproxima-se com as obras de outros autores que dialogaram com esse meio, como foi o caso, por exemplo, em um primeiro momento, de Andre Gunder Frank e de diversos outros autores críticos às análises dualistas das sociedades latino-americanas. Porém, ao contrário de alguns outros autores, como Gonzalez Casanova e Rodolfo Stavenhagen, cujas análises enfocaram elementos étnicos em paralelo ou, às vezes, em contraposição à estrutura de classes das sociedades latino-americanas a partir do que denominaram colonialismo interno, as implicações sociais e culturais do marco e das proposições teóricas de Marini acima destacadas, em especial, foram pouco desenvolvidas nas ciências sociais e na antropologia latino-americana pós-1980.
} 
região. Há, porém, um exemplo, ainda embrionário, do que virá a ser um terceiro tempo, que vai sendo gerado de uma maneira praticamente autônoma de tudo o que vem ocorrendo na região. É como que um 'segundo reverso da medalha'. (...) Trata-se de um investimento de capital que já alcançou muitos milhões de dólares, embora desse total relativamente pouco tenha ficado até agora na região. As autoridades municipais não são consultadas sobre o que vai ocorrendo, as negociações sendo realizadas em altas cúpulas, absolutamente inacessíveis - sem nenhuma exigência de mediação local e sem serem perceptíveis com clareza ao nível local - as quais envolvem grandes interesses capitalistas internacionais. (...) Por enquanto não se pode fazer muito mais do que especular e examinar casos semelhantes, sem muito o que encaixar no quadro atual da região. Todavia, trata-se de fato bem concreto, e o espantoso é que sem ter uma história local, tal como a que viemos traçando neste trabalho, poderá, de repente, alterar o panorama geral de um modo bastante radical. Isso tudo, sem dúvida, será do maior interesse no exame dos efeitos da ação do capitalismo monopolista em regiões subdesenvolvidas, que modifica totalmente a escala de análise, e, no caso particular, faz, inclusive, aparecer em toda a sua nitidez a natureza absolutamente paleotécnica de qualquer exploração mineral anteriormente realizada" (grifos do autor). (Velho, 1972: 143-44).

De fato, nas décadas seguintes, a implantação da indústria da mineração inseriu agentes políticos e econômicos cuja escala de ação diferia bastante das ocupações e frentes anteriores. Esse "terceiro tempo" anunciado por Velho proporcionou uma integração mais profunda entre os agentes de mercado, que, em grande parte, já surgiram como elos subordinados de uma cadeia de produção instituída sistemicamente em escala mundial. No entanto, mesmo quando menos perceptível, essa integração, em último (ou, muitas vezes, em primeiro) caso mundial, já ocorria nas frentes anteriores, como Otávio Velho também observara atentamente desde o início da análise das frentes de expansão, em 1967 (Velho, 1982), em uma interpretação singular da noção sugerida e introduzida na ciência social brasileira por Roberto Cardoso de Oliveira - e, ao menos no caso de Velho (1982 [1969]), também tomando por referência os estudos pioneiros de Caio Prado Jr. (2011 [1942]) a respeito5.

\footnotetext{
5 Em seguida, em sua tese de doutorado, Velho (1976) viria a usar a ideia de "fronteiras em movimento", dentro de um quadro teórico comparativo demarcado por categorias como "desenvolvimento autoritário" em contraste com o que seria um "desenvolvimento burguês-democrático". Recentemente, em uma revisita a esses textos, reconhecendo a importância da pesquisa etnográfica que realizou e, ao mesmo tempo, as limitações do seu contexto de interlocução e produção teórica, sintetizou: "Por isso é que eu digo que a situação é complexa, porque você está se opondo à ditadura militar, mas ao mesmo tempo está sendo contagiado pelo ambiente e pelas questões de uma época, quer você queira, quer não. E que em geral tinham a ver com uma perspectiva desenvolvimentista que se o pretendia caminho da modernidade, e que embora ainda esteja presente entre nós, hoje já pode ser contestada. Até em função dos sintomas mais evidentes de crise produzidos por essa perspectiva". (Velho, 2016: 33). Para uma das primeiras tentativas de sistematização do contexto das experiências de pesquisa do grupo de Velho, ver Almeida (2013).
} 


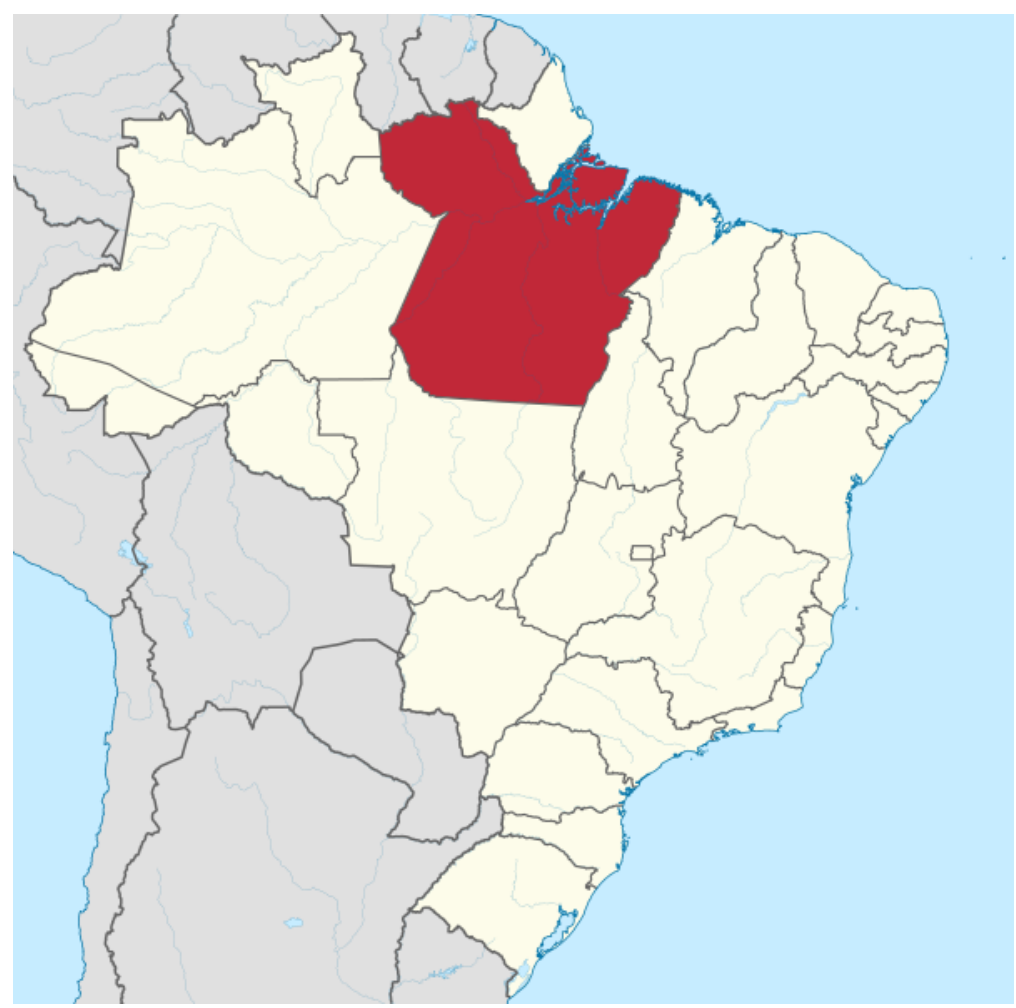

Figura 1: Localização do estado do Pará no Brasil (fonte: https://pt.wikipedia.org/wiki/Pará)

Nesse sentido, o desenvolvimento das frentes de expansão agrícolas na região é um bom exemplo. Ao contrário das frentes de expansão anteriores, extrativistas (borracha, castanha, diamante), formadas por entrepostos de comercialização totalmente voltados para o mercado externo, ou seja, de uma típica economia exportadora, na frente de expansão agrícola que se desenvolvia a partir dos anos 1950, teria surgido a figura do pequeno produtor de terra firme, cuja produção era voltada para o mercado interno de arroz.

Antes disso, confluíam tanto as grandes unidades produtivas quanto a pequena produção. Analisando os seringais do século XIX, por exemplo, Oliveira Filho (1979) notara que:

É através do controle do comércio - e não da expropriação de terras camponesas - que ocorre a subordinação do caboclo amazônico às determinações do grande capital. Necessitando de mercadorias, o pequeno produtor camponês é forçado a dirigir parcialmente seu trabalho para aquelas produções que a rede comercial aceita como pagamento das mercadorias que fornece. No caso da borracha, os altos preços vigentes fazem com que o próprio comércio alternativo e clandestino (como os regatões e marreteiros) pressionem no sentido de que o fornecimento de mercadorias seja pago preferencialmente em seringa. Diante disso ao pequeno produtor só restam logicamente duas opções: ou ele se mantém primordialmente fora da rede de comércio e financiamento, retraindo-se a uma condição próxima a autossubsistência; ou ele se vincula aquela rede, enquadrando-se 
em um sistema flexível, que pode variar de uma ênfase exclusiva na extração até a fixação de uma cota mínima de borracha por cada produtor. Sendo aquela primeira opção meramente teórica, ao caboclo não resta mais que inserir-se no sistema de comércio centralizado e aí, produzindo segundo as normas, procurar exercer uma permanente barganha por vantagens comerciais (Oliveira Filho, 1979: 132-33).

Já no caso da castanha, Velho (1972: 66), por exemplo, assim resumiu a dinâmica dos agentes de mercado:

Existem cerca de seis grupos exportadores importantes em Belém. Com o virtual oligopólio que mantinham, já que até recentemente era praticamente insignificante a parte da castanha consumida no mercado nacional, eram capazes de descarregar boa parte dos efeitos das oscilações de preços no mercado internacional em cima dos grupos de Marabá; os quais, então, buscavam se resguardar levando às últimas consequências o processo de extorsão da maisvalia absoluta.

A partir dos anos 1950, em um primeiro momento, enquanto os grandes produtores ainda produziam principalmente castanha, dedicando-se à pecuária apenas de maneira complementar e subordinada, cujo mercado restringia-se localmente ou a um único centro (Belém), os pequenos produtores independentes (maranhenses-paraenses) produziam um arroz que, a despeito das distâncias, chegava a centros consumidores como o Rio de Janeiro com preços mais baixos que os produzidos em outras regiões do país e que, sendo de pior qualidade, era consumido pela população mais pauperizada das cidades. Esse arroz, porém, cumpria uma função supletiva e complementar no mercado nacional e internacional. Era comercializado quando a produção de arroz no Centro-Oeste abaixava e não era suprida pelo arroz produzido no Rio Grande do Sul, de 
maior preço, voltado para a exportação (Velho, 1972: 123-25). Essa expansão, propositadamente, inclusive, foi considerada como expressão de um "colonialismo interno" no Brasilb.

A nova fase instaurada pela abertura das estradas, exemplificada no trecho acima citado pelo ramal de Marabá à Estrada Belém-Brasília (PA-70), converteria a paisagem dos castanhais da região, em um espaço curto de tempo, em grandes pastagens. Também em um espaço relativamente curto de tempo, a pecuarização integraria os pequenos produtores de arroz dessa frente de expansão aos médios e grandes produtores, primeiro, como fornecedores de pastos (de terra empastada, isto é, transformada em pasto) e, nas décadas seguintes, principalmente a partir dos 1990, quando a pequena produção também se converte à pecuária, em fornecedores de bezerros. Nos arredores das últimas estradas construídas, como a PA-150 (Moju-Redenção, a assim-chamada estrada-tronco do Pará, uma vez que conecta o nordeste ao sudeste do estado), pude observar a mudança no próprio padrão de formação das pastagens por parte dos pequenos produtores dessas frentes de expansão (Felix, 2008). Quando a trajetória anterior previa uma produção de arroz após o primeiro desmate e, apenas depois da colheita, a formação da pastagem, a nova trajetória de pecuarização previa um empastamento direto da mata, sem passar pelo plantio do arroz.

Enfim, passados cinquenta anos de seu início, o processo de desenvolvimento da frente de expansão agrícola no sul e sudeste do Pará configurou unidades de produção profundamente integradas na atual cadeia produtiva da carne e de produtos lácteos em geral, em especial a partir de sua pecuarização. A pequena produção pecuária fornece leite de baixa qualidade e a baixo custo para laticínios que se instalaram na região, principalmente a partir de incentivos fiscais, políticas de financiamento de bancos públicos e diversos subsídios das prefeituras. Neste caso,

6 A noção de colonialismo interno esteve relacionada à origem do estudo sistemático das frentes de expansão. Criada no âmbito das ciências sociais latino-americanas em contraposição às teorias dualistas, ou de sociedade dual, e tendo textos de Pablo Gonzalez Casanova e de Rodolfo Stavenhagen como referências seminais principais (Stavenhagen, 1963; 1981; Casanova, 2009; Chaloult, 1978), foi proposta no Brasil por Roberto Cardoso de Oliveira (1978 [1966]) e difundida, em especial, a partir do Projeto "Estudo do colonialismo interno no Brasil", coordenado por ele. Para tanto, teriam tido importância, por exemplo, o Centro Latinoamericano de Investigaciones en Ciencias Sociales e a Revista vinculada ao Centro, em que Stavenhagen e Casanova publicaram (Cf. Centro, 1969). Stavenhagen, particularmente, ao longo dos dois anos que ficou no Rio de Janeiro, teria formulado sua definição do conceito e iniciado a amizade que manteve com Cardoso de Oliveira (Cf. Stavenhagen, 2010; 2018). Foi a partir desse Projeto e dos seus trabalhos que essa noção e a de fricção interétnica se constituíram como referências iniciais para os estudos sistemáticos das frentes de expansão realizados por Cardoso de Oliveira e seus assistentes e orientandos. Mais tarde, em 1993, ele elaboraria essa narrativa: 'A genealogia do conceito de 'colonialismo interno' pode ser traçada, talvez, a partir de autores como Gunnar Myrdal e C. Wright Mills, alcançando sua formulação latino-americana mais consistente com Pablo Casanova, em seu artigo de 1963, 'Sociedad plural, colonialismo interno y desarrollo' (America Latina, año 6, n 3) ou em seu livro Sociología de la explotación, no capitulo 'El colonialismo interno'. Rodolfo Stavenhagen, com 'Siete tesis equivocadas sobre America Latina' (Politica Independiente, $\mathrm{n}^{\circ} 1$, maio de 1965), acrescenta considerações interessantes à teoria dualista de J. Lambert, mostrando a necessidade de criticá-la do ponto de vista do colonialismo interno. Inspirado nesses autores, tive a oportunidade de tratar o problema em meu 'A noção de 'colonialismo interno' na etnologia' (...)" (Cardoso de Oliveira, 2006: 41, nota 5). Casanova, por sua vez, em artigo de 2006 no qual propôs uma redefinição do conceito, credita sua origem às ideias de Lenin - ainda que a expressão tenha sido originalmente empregada por Mills e assim explicou sua elaboração: "Cuando la noción de colonialismo interno fue formulada de manera más sistemática en América Latina, su vinculación con la lucha de clases y el poder del Estado apareció originalmente velada. En La democracia en México sostuve la tesis de que en el interior de dicho país se daban relaciones sociales de tipo colonial. "Rechazando que el colonialismo sólo debe contemplarse a escala internacional", afirmé que este también "se da en el interior de una misma nación, en la medida en que hay en ella una heterogeneidad étnica, en que se ligan determinadas etnias con los grupos y clases dominantes, y otras con los dominados" (González Casanova, 1965). Ya en un artículo de 1963 había analizado el concepto a nivel interno e internacional, que luego amplié en 1969 en ensayos sobre Sociología de la explotación (González Casanova, 1987). En esos trabajos se precisaron los vínculos entre clases, imperialismo, colonialismo y colonialismo interno. También se amplió el alcance de este último, y se lo relacionó con las diferencias regionales en la explotación de los trabajadores y con las transferencias de excedente de las regiones dominadas a las dominantes. El planteamiento correspondió a esfuerzos semejantes que fueron precedidos por C. Wright Mills (1963: 154), quien de hecho fue el primero en usar la expresión "colonialismo interno"." (Casanova, 2006: 415). 
além de financiamentos para a instalação dos principais grupos, todas as empresas foram beneficiadas, por exemplo, com a redução do ICMS sobre produtos industrializados de origem láctea de $12 \%$ para $2 \%$ no final dos anos 1990 (Alves, 2007). Houve ainda a instalação de um número considerável de indústrias informais, conhecidas como queijarias, que também captam leite de pequenos produtores e que, muitas vezes, sequer atendem ao baixo nível sanitário da produção dos pequenos laticínios formais.

Ao menos até 2007, esses produtos lácteos abasteciam, em especial, centros consumidores em outras regiões do país, possivelmente atendendo a uma lógica de mercado semelhante à integração sistêmica que ocorrera com o arroz maranhense-paraense. No entanto, esses pequenos produtores também fornecem bezerros para médios e grandes proprietários, integrando-se, sobretudo através deles, à produção de carne realizada nos grandes frigoríficos que se instalaram na região visando a exportação.

Já nos últimos anos, no entanto, a vinculação ao mercado mundial é direta e praticamente completa. A atual distribuição de frigoríficos e laticínios cadastrados com produtos autorizados para exportação abrange toda a região, tal como se verifica na listagem disponível na página eletrônica do MAPA, incluindo até mesmo os produtos lácteos (MAPA, s/d). Nesta, há frigoríficos e laticínios cadastrados nos municípios de Marabá, Rio Maria, Eldorado dos Carajás, Santana do Araguaia, Redenção, Xinguara, Tucumã, Ourilândia do Norte, Água Azul do Norte, São Felix do Xingu, Itupiranga, Piçarra, Sapucaia, Cumaru do Norte, São Joao do Araguaia, Novo Repartimento, Santa Maria das Barreiras, Dom Eliseu, Açailândia, Altamira, Rondon do Pará, São Geraldo do Araguaia e Conceição do Araguaia. Dentre estes, se destacam os seis frigoríficos da empresa JBS S/A (Eldorado, Marabá, Redenção, Santana do Araguaia, Altamira e Tucumã) e a região da rodovia PA-279, que, por exemplo, só em Tucumã concentra tanto uma unidade da empresa JBS quanto uma da empresa Marfrig - as duas maiores empresas exportadoras de carne bovina no país - além de duas unidades da empresa Frigol (Água Azul do Norte e São Felix do Xingu), de mais três estabelecimentos em Xinguara e de outros dois em Ourilândia do Norte.

A última fase dessa frente agropecuária, entretanto, se desenvolveu em um contexto de abertura de novas estradas, de fomento a grandes empreendimentos agropecuários e de financiamento, em especial, da pecuária por parte de bancos públicos, agências e programas de desenvolvimento. O chamado tempo das estradas significou a exploração e uma transformação definitiva dos vales do Rio Tocantins, do Rio Araguaia e de seus vários afluentes, principalmente a partir das cidades e povoados estabelecidos durante as fases de construção e de abertura das rodovias. Remonta, nesse caso, à construção da Rodovia Belém-Brasília (BR-010, em 1956-58) e suas vicinais, em 1960, do denominado ramal de Marabá (PA-70, atual BR-222), da Transamazônica (BR-230, em 1972), e da BR-153 (antiga OP-02, aberta pelo regime militar para reprimir a Guerrilha do Araguaia, em 1970), assim como das mais modernas, PA-150 (BR-155) e PA-279 (que estenderia a expansão para o Rio Xingu), nos anos 1980, e da BR-158 (RedençãoSantana do Araguaia). Dessa maneira, o fomento dos grandes empreendimentos agropecuários advém de uma série de políticas e sucessivos programas de desenvolvimento levados a cabo por agentes estatais e grandes agentes financeiros, a partir da transformação da Superintendência do Plano de Valorização Econômica da Amazônia (SPVEA) em Superintendência do 
Desenvolvimento da Amazônia (SUDAM), em 1966, do Banco de Crédito da Amazônia (BCA S/A) em Banco da Amazônia (BASA S/A), em1966, e de uma agência do Banco do Brasil em Marabá, em 1964, entre outras medidas nos anos seguintes. Santos (2011: 65), por exemplo, cita que, em 1960, existiam 33 estabelecimentos com mais de 10 mil hectares. Em 1980, já seriam 199 estabelecimentos, responsáveis pela propriedade de $35,8 \%$ das terras ocupadas do estado do Pará.

Essa fase já se desenvolve em meio ao terceiro tempo anunciado por Velho (1972), caracterizado pelo advento dos grandes projetos da indústria da mineração e demais intervenções planejadas associadas, como as hidrelétricas e algumas indústrias mínero-metalúrgicas. O Projeto Ferro Carajás, junto à Mineração Rio do Norte (exploração de bauxita), inaugurada em 1978 em Porto Trombetas (Oriximiná/PA) demarcariam a implantação da mineração industrial sob a forma de grandes projetos a partir dos anos 1970, aumentando a escala de outros projetos isolados anteriores, como a citada Icomi na Serra do Navio/AP (manganês), em operação desde 1957, em uma associação com a gigante norte-americana Bethlehem Steel (Monteiro, 2005). Além das minas, os grandes projetos implicam a construção de infraestrutura logística e urbanística: portos, ferrovia, estradas, vilas residenciais, aeroportos, cidades, linhas de transmissão de energia etc.

O Programa Grande Carajás (PGC), em 1980, consolidaria o início de uma sucessão de grandes projetos, em especial, o complexo mina-ferrovia-porto (o Projeto Ferro Carajás, a Estrada de Ferro Carajás e o Porto de Ponta da Madeira, em São Luís/MA), a Usina Hidrelétrica de Tucuruí e a produção de alumina e alumínio em Barcarena, no estado do Pará (empresas Albras e Alunorte) e em São Luís, no estado do Maranhão (empresa Alumar) ${ }^{7}$.

Em certo sentido, esse denominado tempo dos grandes projetos se estende até os dias atuais, uma vez que a abertura de novas minas nos arredores de Carajás na última década com alguma especificidade, embora, também, com características fundamentalmente semelhantes (Felix, 2019). Essa nova expansão, inclusive, é um desdobramento de projetos de exploração mineral previstos desde as primeiras pesquisas e títulos minerários adquiridos nos anos 1960 e 1970. Hebette (2004, vol. III) relata, por exemplo, que em 1985 praticamente todo o território já havia sido explorado, titulado e loteado (pedidos e requisições de pesquisa, concessões de lavra).

Tomados enquanto uma forma de produção, em geral, os grandes projetos significam uma acumulação de capital centralizada em larga escala, vinculada a interesses políticos e econômicos nacionais e internacionais. No entanto, uma vez incidentes sobre economias dependentes, o que frequentemente é o caso, um de seus efeitos seria a reprodução da dependência. Ribeiro (1987: 4-5), analisando os efeitos dos grandes projetos, por exemplo, afirma que, apesar de não haver um conhecimento substancial a respeito de seus processos de execução e de sua relação com o desenvolvimento econômico, "[os projetos de grande escala, PGE] Costumam, portanto, reforçar disparidades econômicas preexistentes tanto no âmbito de uma determinada sociedade quanto em termos das relações entre distintas regiões econômicas". $E$, em resumo, que: "A dinâmica

\footnotetext{
7 Sobre o PGC, ver, por exemplo, Almeida Jr. (1986), que reuniu artigos de ciências variadas em torno da ecologia da intervenção na época e, por outro lado, para um balanço mais recente (ainda quando a empresa Vale divulgava interesse na implantação de uma siderúrgica em Marabá), ver Carneiro (2013).
} 
típica dos PGE termina por replicar a dependência político-econômica, sobretudo quando estão em jogo relações com países pouco ou não industrializados".

O contexto em que se desenvolve essa última fase das frentes de expansão agropecuárias e o tempo dos grandes projetos, no entanto, dados os novos agentes envolvidos e a escala dos eventos em jogo, compreende transformações mais amplas das relações de dependência na região. A citada associação entre a antiga Companhia Vale do Rio Doce e a United States Steel e, em seguida, o Banco Mundial (Programa Grande Carajás), bem como a formação das grandes inversões de capital dos grandes projetos associados seguintes, são realizados em um contexto de profunda aliança do grande capital nacional e estrangeiro impulsionados pelo regime político pós-1964, que, como propôs Marini (1974), não se deve a um simples efeito da ação do imperialismo dos EUA, entendido enquanto um fator externo às sociedades latino-americanas, mas sim a desdobramentos de um desenvolvimento integrado, inclusive, de seus sistemas de produção. E os grandes projetos da indústria da mineração no estado do Pará são, nesse sentido, a ponta de lança de interesses necessariamente relacionados a uma rede global de produção, tendo, nesse caso, dupla vinculação intrínseca ao mercado mundial: o fato de se constituir na forma de grandes projetos e o fato de produzirem novas minas.

Na última década, em um contexto no qual a América Latina foi reconvertida em uma economia exportadora na nova divisão internacional do trabalho e houve expansão da megamineração realizada por empresas transnacionais em vários países (Cf., dentre outros, Svampa e Antonelli, 2010; Delgado Ramos, 2010, 2013; Seoane, 2013), antigos projetos de exploração da província mineral de Carajás foram retomados com a alta dos preços dos minérios no mercado mundial. Agora, porém, sob os marcos regulatórios de inspiração neoliberal definidos nos anos $1990^{8}$ e após a privatização da antiga empresa CVRD (1997), renomeada, desde 2007, para Vale somente ${ }^{9}$.

Além da megamineração a céu aberto, outros setores associados também se expandiram, como foi o caso da produção de ferro-gusa. Todavia, poucas guseiras resistiram à crise econômica mundial de 2008 e até mesmo um anunciado projeto de instalação de uma grande siderúrgica em Marabá foi provisoriamente abortado pela empresa Vale, cujos investimentos, no entanto, não se reduziram. Voltaram-se, exclusivamente, para a mineração: para a aquisição e para a abertura de novas minas em todo o mundo.

No que se refere à reconcentração estratégica da empresa Vale pós-crise, cabe ressaltar a venda das ações de empresas como a Alunorte e a Albras (mina de bauxita em Paragominas/PA, refinaria de alumina e fábrica de alumínio em Barcarena/PA), para a Hydro, transnacional com

\footnotetext{
8 Plano Nacional de Desenvolvimento (Lei 8031/90); CFEM (Decreto n¹/91); reformas constitucionais de 1995 (Emendas Const. No 6 e 9/95); Lei Kandir (Lei n 87/96). Em outros países da América Latina, algumas legislações minerais foram redefinidas nos anos 2000, visando principalmente maior recolhimento fiscal. No Brasil, está em discussão no parlamento um novo marco legal para o setor e o projeto inicial do mesmo teria atendido principalmente aos interesses das grandes mineradoras (Malerba et al., 2012).

${ }^{9}$ Houve, portanto, mais continuidade do que ruptura ao longo desse processo de integração econômica do denominado tempo dos grandes projetos. Isso se verifica, por exemplo, na agência econômica do Estado, ainda que, no neoliberalismo, não se predique ao agente estatal um papel de gestor direto do capital. Pesquisadores que investigaram a ação estatal na Amazônia Oriental desde 1964, como Santos (2009), acentuaram mais similitudes e complementariedades do que necessariamente rompimento entre os modelos adotados no período ditatorial e pós-ditatorial, em especial, no que se refere ao planejamento e promoção das ideologia econômicas desenvolvimentistas.
} 
sede na Noruega, em 2011, e, um ano antes, da Pará Pigmentos S/A (produção de caulim) para o Grupo Imerys, que tem sede na França (Cf. Hydro, 2016; Imerys, s/d; Imerys, 2016). Tais reconfigurações acionárias no Brasil se inserem em estratégias de mercado global da Vale e dessas transnacionais que devem ser observadas pelo leitor, embora sua análise fuja ao escopo desse artigo. Também vale mencionar que em meio ao contexto pandêmico recente, o setor da mineração, sob a liderança da empresa Vale, não interrompeu suas atividades produtivas, a despeito dos diversos casos de adoecimento dos trabalhadores e do entorno, como foi o caso da cidade de Parauapebas e de todo o seu sistema minerário situado nas regiões Norte e Sudeste do Brasil.

Já no setor guseiro atrelado ao pólo de Carajás, seis das onze empresas fecharam e mais de 3 mil trabalhadores foram demitidos (Milanez, 2012). Em entrevista com o presidente do Sindicato dos Trabalhadores nas Indústrias Metalúrgicas, Mecânicas, de Material Eletrônico, Eletroeletrônico, Informática e Similares do Município de Marabá (Simetal Marabá), fui informado que praticamente todos os trabalhadores da única metalúrgica guseira de propriedade da empresa Vale na região também foram demitidos, restando cerca de apenas 20 , que não foram demitidos porque teriam ainda alguma estabilidade laboral garantida devido a comprovado estado de adoecimento no trabalho (Felix, 2019). Após a crise de 2008, a Vale demitiu 1,3 mil trabalhadores diretos no Brasil, principalmente nas unidades do estado de Minas Gerais, e deu férias coletivas a outros 5,5 mil (Milanez, 2012). Também teria demitido cerca de 12 mil terceirizados (Cf. Articulação Internacional dos Atingidos pela Vale, 2010)10.

Sendo assim, enquanto grandes projetos, sucessivas construções envolveram grandes contingentes de trabalhadores, por curtos períodos. O auge da construção do Projeto Ferro Carajás utilizou cerca de 28 mil trabalhadores em 1982 (Roberts, 1995; Castro, 1994). Nas obras da Usina Hidrelétrica de Tucuruí (1975-1984), teriam sido 30 mil trabalhadores, sendo que aproximadamente 60 mil pessoas se deslocaram para a cidade de Tucuruí em busca de trabalho. Na cidade de Barcarena, na construção das empresas Albras e da Alunorte, foram contabilizados cerca de 12 mil trabalhadores, em outubro de 1984, e a cidade recebeu cerca de 100 mil pessoas em poucos anos. No entanto, no ano seguinte, em 1985, com a primeira parte das obras concluídas, o número de trabalhadores na construção civil reduziu quase à metade (Fontes, 2003). A origem desses trabalhadores recrutados para as posições mais baixas do mercado de trabalho da construção dos grandes projetos era diversa, assim como seus destinos, terminados os trabalhos, foram descritos como difusos.

Pelos dados e pesquisas realizadas sobre o contexto da última década, a expansão das atividades da construção de hidrelétricas e da indústria da mineração, por exemplo, também mobilizou contingentes populacionais significativos para algumas cidades, articulada a um discurso ideológico de promoção do denominado desenvolvimento local e/ou sustentável, enquanto medida de suposta superação de determinadas dinâmicas sociais presentes nas atividades antes economicamente predominantes.

\footnotetext{
10 Para uma análise a respeito da constituição do setor guseiro antes da crise, ver, dentre outros, Carneiro (2008) e Monteiro (1998; 2006). Para uma análise a respeito das estratégias empresariais imediatas do setor guseiro na região de Açailândia/MA, ver Carneiro e Ramalho (2009).
} 
Porém, considerando salários, condições de trabalho e de exploração da força de trabalho, como duração da jornada de trabalho e intensidade do trabalho, é possível indicar que o recrutamento desses trabalhadores, assim como sua expulsão e circulação em momento posterior, foi dado sob o regime de superexploração do trabalho que fundamenta o ciclo do capital nas formações dependentes (Felix, 2019a).

\section{Amazonização do trabalho e capitalismo hoje: qual margem?}

Neste sentido, epistemologias comprometidas com perspectivas de superação desses regimes e da condição de dependência por meio da introdução de maior produtividade capitalista do trabalho perderam poder explicativo para a análise do contexto amazônico brasileiro frente ao quadro das condições de vida e trabalho dos trabalhadores e da população atingida pelos grandes projetos em geral. Da mesma forma, as teorias que se pautavam pela tese de que o Estado seria ausente ou insuficiente nessas regiões demonstraram que estavam mais baseadas em uma expectativa idealizada pelo próprio pesquisador/a a respeito do que seria uma agência estatal adequada do que necessariamente na análise da agência estatal concreta ao longo do desenvolvimento das diversas frentes de expansão, em especial, para a implantação das empresas agropecuárias e da mineração transnacional.

Contudo, essas epistemologias também ficam cada vez mais esvaziadas diante do quadro de descenso das condições de vida e trabalho anteriormente oferecidas fora dos chamados rincões, considerando o sentido do processo de transformações do mundo do trabalho fora dessa região considerada periférica e, não raro, exótica diante de outros contextos. Atualmente, além da construção civil e da agropecuária, é também possível indicar essas características de um regime de superexploração do trabalho para frações cada vez mais amplas de trabalhadores em decorrência da forma como as empresas vêm adotando gestões flexíveis da força de trabalho em praticamente todos os setores econômicos e processos produtivos, abrangendo também, por exemplo, os trabalhadores da mineração, dos transportes, da metalurgia e dos serviços em geral (Felix, 2018; 2019; 2020).

As transformações do mundo do trabalho, em especial, após a crise capitalista mundial dos anos 1970 e, mais recentemente, após a crise de 2008 instauraram processos importantes de mudança nas formações sociais centrais e dependentes. A observação de um processo de precarização do trabalho cada vez mais generalizado em todo o mundo confundiu e complexificou ambas, inaugurando um período de reanálise das teorias formuladas ao longo do século XX.

As mudanças no que outrora era associado a uma condição operária formalmente regulada, estável e fixa, que teria caracterizado fração considerável da classe trabalhadora situada nas economias centrais, vêm motivando novas propostas teóricas para os estudos do trabalho. A erosão de uma condição operária anteriormente associada ao pacto fordista europeu e norte-americano, por exemplo, motivou abordagens realizadas por pesquisadores europeus e estadunidenses a respeito de um "retorno da superexploração", da crise da "sociedade salarial" 
ou, mais recentemente, da emergência de uma "nova classe social" que estaria se mundializando (Harvey, 2008; Castel, 1998; Standing, 2011) ${ }^{11}$.

Nos países dependentes, em que, quando observada, tal condição operária pretérita abarcava apenas uma fração estatisticamente minoritária do próprio conjunto do proletariado, o processo de transformações colocadas pelo advento da chamada acumulação flexível do capital também vem sendo analisado, mas sob outros matizes. Porém, devido a um enviesamento ideológico, fruto de uma determinada mitologia apologética burguesa da história do desenvolvimento do capitalismo, as formações sociais dependentes durante grande parte do século XX tiveram menor importância teórica, tendo suas especificidades pensadas quase sempre como resquícios de uma história universal em superação e/ou em extinção, no rumo do que já se teria superado nos países centrais e, portanto, do que mais cedo ou mais tarde iria se superar nas periferias também.

Atualmente, qualquer desconhecimento empírico e, por conseguinte, menosprezo teórico dessas formações sociais, ou seja, qualquer esquema teórico que não leve em conta a totalidade das transformações no mundo do trabalho tem reduzidíssimo alcance para a explicação das suas próprias paróquias. $\mathrm{E}$, nesse sentido, o que anteriormente se apresentava com pouca importância empírica e teórica talvez hoje seja um ponto de referência com cada vez melhor perspectiva e maior poder explicativo para a observação dos processos sociais concretos mundiais que estão em curso. Dessa forma, teleologias baseadas em estudos que privilegiam analiticamente $o$ capitalismo avançado de maneira desconexa e/ou atemporânea das formações dependentes também ficam cada vez mais esvaziadas diante do quadro de descenso das condições de vida e trabalho nos próprios países centrais imperialistas. Atualmente, para aqueles que tomaram essa perspectiva, o sentido da modernidade, portanto, aparenta estar invertido, mais no que são consideradas as margens do que no centro do capitalismo.

Nesse sentido, dado um quadro de precarização das condições de trabalho dos trabalhadores nas últimas décadas, conforme atestaram, dentre outros, organismos como a Organização Internacional do Trabalho (ILO, 2015), alguns autores têm se voltado para teorias outrora pensadas no âmbito das ciências sociais latino-americanas, que, particularmente a partir dos anos 1960, juntos aos partidos e movimentos revolucionários, propuseram interpretações originais para a compreensão das formações sociais dos seus próprios países de forma crítica a epistemologias dogmáticas, eurocêntricas e/ou não-sistêmicas do capitalismo mundial, como foi o caso daqueles que se afiliaram ao debate da dependência e, em especial, do brasileiro Ruy Mauro Marini, cujas teorias aqui nos referimos como fundamento para uma reanálise do capitalismo na Amazônia. Portanto, não por acaso, as teses do que este autor denominou como teoria marxista da dependência têm sido objeto de interesse recente na literatura científica escrita em língua inglesa - tal como o atestam publicações recentes como Smith (2016), Sotelo (2016) e Kufakurinani et al. (2017) - e, por outro lado, o debate sobre o seu conceito de superexploração do trabalho veio novamente à tona na América Latina a partir da objeção ou revisão de alguns

\footnotetext{
11 Em consonância com esses pesquisadores, alguns autores brasileiros também analisaram esse processo e, em especial, nos últimos anos consideraram estar em curso um processo mundial de emergência do chamado precariado, sob diferentes enfoques (Alves, 2014; Braga, 2017; Antunes, 2018).
} 
críticos e de seus respectivos replicadores nos últimos anos (Carcanholo, 2013; Katz, 2017; Sotelo, 2017; Osorio, 2017).

A originalidade das suas premissas está na compreensão da especificidade das formações latino-americanas e da reprodução do ciclo do capital nas economias dependentes, tomando-as não como expressões atemporâneas do capitalismo forâneo, mas como coetâneas e sistêmicas em relação ao tempo histórico e ao modo de produção capitalista mundial. E, portanto, crítico das ideologias de viés desenvolvimentista que, por exemplo, na América Latina, importavam um modelo narrativo eurocêntrico da formação histórica dos países centrais ou avançados e que, hoje, demonstra-se equivocado tanto para a compreensão dos processos históricos da formação latino-americana, africana e asiática, quanto, inclusive, para a compreensão dos processos históricos dos próprios países centrais que se tomava por objeto generalizante.

A desconstrução científica dessas teses foi possível, justamente, quando Marini, por exemplo, em Dialéctica de la dependencia e em seus escritos do mesmo período, dimensionou teoricamente com propriedade a esfera da circulação e, historicamente, a onipresença do mercado mundial: "Es por lo que, más que un precapitalismo, lo que se tiene es un capitalismo sui generis que sólo cobra sentido si lo contemplamos en la perspectiva del sistema en su conjunto, tanto a nivel nacional como, y principalmente, a nivel internacional." (Marini, 1973).

\section{Considerações finais}

Neste artigo, em resumo, analisamos: 1) o processo histórico da expansão das frentes de expansão na Amazônia brasileira e, particularmente, da dinâmica e dos agentes presentes após o advento da implantação da grande indústria da mineração no estado do Pará; 2) os elementos que denotam as continuidades e, também, aqueles que permitiram diferir o advento dessa indústria em face dos elementos já presentes nas frentes anteriores; 3) o enfraquecimento teórico das epistemologias de superação dos regimes de superexploração do trabalho que se pautavam pelo aumento da produtividade capitalista do trabalho e pelas teses que se pautavam pela suposta ausência de Estado em determinadas regiões consideradas economicamente e/ou culturalmente atrasadas do país; 4) a relação entre o processo mundial de precarização do trabalho e o processo de releituras das teorias formuladas ao longo do século $\mathrm{XX}$, em especial, daquelas que apreenderam as formações sociais latino-americanas de modo internacionalmente sistêmico e coetâneo, como foi o caso da obra de Ruy Mauro Marini.

Portanto, é no sentido abordado acima que concluímos que asserções como retorno da superexploração (no sentido de que estaria extinta e/ou em extinção), fim da sociedade salarial ou, ainda, tal como se propôs mais recentemente, emergência de uma nova classe social, demonstram um viés eurocêntrico para aqueles que, a partir das formações dependentes ou periféricas, necessariamente, tiveram que apreender o sistema em seu conjunto para entender o que estruturalmente fundamentava o aparente atraso capitalista ou a composição social complexa ou aparentemente heterogênea do proletariado em seus países. E é nesse sentido também que, a partir das premissas aqui ressaltadas, o legado dos aportes da chamada teoria marxista da 
dependência, ao contrário do sentido que foi apontado pelos seus críticos nos anos 1970, seja, justamente, não só historicamente interessante, mas, sobretudo, teoricamente relevante hoje.

\section{Referências bibliográficas:}

ALMEIDA, Alfredo W. B. A 'turma do Brasil Central' e a 'Antropologia da Amazônia'. En O. Velho, Frentes de expansão e estrutura agrária. Manaus: UEA, 2013.

ALMEIDA JR., José Gonçalves. Desafio Político, Ecologia e Desenvolvimento. São Paulo: Brasiliense, 1986.

ALVES, Giovanni. (2014). Trabalho e neodesenvolvimentismo. Bauru: Canal 6, 2014.

ALVES, Lívia. Arranjo produtivo local do leite do sudeste do Pará. En: Plano de Desenvolvimento Sustentável da Amazônia legal: PDSA 2005-2008. Belém: Agência de Desenvolvimento da Amazônia, 2017.

ANTUNES, Ricardo. O privilégio da servidão. São Paulo: Bolotempo, 2018.

ARTICULAÇÃO INTERNACIONAL DOS ATINGIDOS PELA VALE. Dossiê dos impactos e violações da Vale no mundo. I Encontro Internacional dos Atingidos pela Vale. Rio de Janeiro: Articulação Internacional dos Atingidos pela Vale, 2010.

BRAGA, Ruy. A rebeldia do precariado. São Paulo: Bolortempo, 2017.

CARCANHOLO, Marcelo. (Im)precisiones acerca de la categoría superexplotación de la fuerza de trabajo. Razón y Revolución, No. 25, pp. 91-124, 2013.

CARDOSO DE OLIVEIRA, Roberto. A noção de 'colonialismo interno' na etnologia [1966]. En Cardoso de Oliveira, A sociologia do Brasil indígena. Rio de Janeiro/Brasília: Tempo Brasileiro/ Editora da UnB, 1978.

CARDOSO DE OLIVEIRA, Roberto. O movimento dos conceitos na antropologia [1993]. En Cardoso de Oliveira, O trabalho do antropólogo. São Paulo: UNESP, 2006.

CARNEIRO, Marcelo. Mineração, siderurgia e desenvolvimento na Amazônia Oriental: um balanço da experiência do programa grande Carajás. En: Carneiro, Terra, trabalho e poder. São Paulo: Analblume, 2013.

CARNEIRO, Marcelo. Crítica social e responsabilização empresarial. Cadernos CRH, Vol.21 (53), pp. 319-331, 2008. 
CARNEIRO, M.; Ramalho, J. R. A crise econômica mundial e seu impacto sobre o setor siderúrgico maranhense. En Carneiro e Costa (orgs.), A terceira margem do rio. São Luis: EdUFMA, 2009.

CASANOVA, Pablo González. Colonialismo interno (una redefinición). En: Boron, Amadeo y González, La teoría marxista hoy. Problemas e perspectivas. Buenos Aires: CLACSO, 2006.

CASANOVA, Pablo González. El colonialismo interno [1969]. En Casanova, De la sociología del poder a la sociología de la explotación: pensar América Latina en el siglo XXI. Bogotá: Siglo del Hombre Editores y Clacso, 2009.

CASTEL, Robert. As metamorfoses da questão social. Petrópolis: Vozes, 1998.

CASTRO, Edna. Industrialização, transformações sociais e mercado de trabalho. Papers do NAEA, 23, 1994.

CENTRO LATINOAMERICANO DE INVESTIGACIONES EN CIENCIAS SOCIALES. Diez años de actividades. Revista Mexicana de Sociología, Vol. 31 (2), pp. 457-483, 1969.

CHALOULT, Yves. Estado, acumulação e colonialismo interno. Petrópolis: Vozes, 1978.

DELGADO RAMOS, Gian Carlo. (ed). Ecología política de la minería en América Latina. Mexico: CIICH/UNAM, 2010.

DELGADO RAMOS, Gian Carlo. (ed). Ecología política del extractivismo en América Latina. Buenos Aires: Clacso, 2013.

ENTREVISTA COM R. STAVENHAGEN. Soc. e Cult., Vol. 13(1), pp. 137-142, 2010.

FELIX, Gil. O caminho do mundo: mobilidade espacial e condição camponesa em uma região da Amazônia Oriental. Niterói: Editora da UFF, 2008.

FELIX, Gil. Circulación y superexplotación del trabajo. Sociología del trabajo, 92, pp. 87-105, 2018.

FELIX, Gil. Mobilidade e superexploração do trabalho: o enigma da circulação. Rio de Janeiro: FAPESP/Lamparina, 2019. 
FELIX, Gil. Sobre o conceito de exército industrial de reserva em Ruy Mauro Marini. En Felix, Mobilidade e superexploração do trabalho: o enigma da circulação. Rio de Janeiro: FAPESP/ Lamparina, 2019a.

FELIX, Gil. Super-circulation: towards a political economy of platformisation. Critical Sociology, Vol. 46 (7-8):, pp. 1221-1232, 2020.

FELIX, Gil; Sotelo Valencia, Adrián. A superexploração do trabalho: uma perspectiva da precariedade e da condição proletária a partir da teoria da dependência. Astrolabio Nueva Época, 23, pp. 1-26, 2019.

FELIX, Gil; Guanais, Juliana. Superexplotación del trabajo en el siglo XXI. Bremen: El Tiple, 2019.

FONTES, Edilza. O peão de trecho e o peão de casa: identidade operária entre os trabalhadores da construção civil de Barcarena no canteiro de obras da Albras/Alunorte. Novos Cadernos NAEA, Vol. 6(1), pp. 65-82, 2003.

HARVEY, David. Condição pós-moderna. São Paulo: Loyola, 2008.

HEBETTE, Jean. Cruzando a fronteira: 30 anos de estudo do campesinato na Amazônia. (4 vols.). Belém: EdUFPA, 2004.

HYDRO S/A. Hydro no Brasil. Disponível em: http://www.hydro.com/pt/A-Hydro-no-Brasil/Sobre-aHydro/A-Hydro-no-Brasil/ . 2016.

INTERNATIONAL LABOUR ORGANISATION. World Employment and Social Outlook 2015: The Changing Nature of Jobs. Geneva: International Labour Office, 2015.

IMERYS S/A. Imerys no Pará. Disponível em: http://www.imerys.com.br/content/5/imeryscarbonatos, s.d.

IMERYS S/A. Presentation du groupe. Disponível em: http://www.imerys.com/scopi/group/ imeryscom/imeryscom.nsf . 2016.

KATZ, Claudio. Aciertos y problemas de la superexplotación. Disponível em: http:// katz.lahaine.org/b2-img/ACIERTOSYPROBLEMASDELASUPEREXPLOTACIN.pdf. (Acessado em 12 janeiro 2021). 2017.

KUFAKURINANI, Ushehwedu et al. (eds). Dialogues on development (vol. 1: dependency). New York: Institute for New Economic Thinking, 2017. 
MALERBA, Julianna et al. (org). Novo Marco legal da mineração no Brasil: para quê? Para quem? Rio de Janeiro: FASE, 2012.

MINISTÉRIO DA AGRICULTURA E PECUÁRIA E ABASTECIMENTO. Listas de Estabelecimentos Nacionais Habilitados à Exportação por País. Disponível em: http://sigsif.agricultura.gov.br/ sigsif_cons/!ap_exportador_nac_pais_rep_net. s/d.

MARINI, Ruy Mauro. Subdesarrollo y revolución. Mexico: Siglo XXI Editores, 1974.

MARINI, R. M. Dialéctica de la dependencia. Mexico: Era, 1973.

MARINI, R. M. En torno a Dialéctica de la dependencia (postscriptum). En Marini, Dialéctica de la dependencia. Mexico: Era, 1973a.

MARINI, R. M. El ciclo del capital en la economía dependiente. En: Oswald (coord), Mercado y dependencia. Mexico: Nueva Imagen, 1979.

MARINI, R. M. Proceso y tendencias de la globalización capitalista. En Marini y Millán (orgs), La teoría social latinoamericana, t. IV: Cuestiones contemporáneas. México: UNAM/FCPyS/ CELA, 1996.

MILANEZ, Bruno. O novo marco legal da mineração: contexto, mitos e riscos. En Mallerba (org), Novo marco legal da mineração: para quê? Para quem?. Rio de Janeiro: FASE, 2012.

MONTEIRO, Maurílio. Siderurgia e carvoejamento na Amazônia. Belém: NAEA/UFPA, 1998.

MONTEIRO, Maurílio. Meio século de mineração industrial na Amazônia e suas implicações para o desenvolvimento regional. Estudos Avançados, Vol. 19 (53), pp. 187-207, 2005.

MONTEIRO, Maurílio. Em busca de carvão vegetal barato: o deslocamento de siderúrgicas para a Amazônia. Novos Cadernos do NAEA. Vol. 9 (2), pp. 55-97, 2006.

OLIVEIRA FILHO, João P. O caboclo e o brabo: notas sobre duas modalidades de força de trabalho na expansão da fronteira amazônica do século XIX. En Silveira (org.), Encontros com a civilização brasileira. Rio de Janeiro: Civilização Brasileira, 1979.

OSORIO, Jaime. Teoría marxista de la dependencia sin superexplotación. Una propuesta de desarme teórico para avanzar. Disponível em: http://marxismoyrevolucion.org/wp-content/ uploads/2017/09/Teor\%C3\%ADa-marxista-de-la-dependencia-sin-superexplotación.pdf. (Acessado em 12 janeiro 2021). 2017. 
PRADO JUNIOR, Caio. Formação do Brasil contemporâneo. São Paulo: Cia. das Letras, 2011.

RIBEIRO, Gustavo Lins. Cuanto más grande mejor?' Proyectos de Gran Escala: una forma de producción vinculada a la expansión de sistemas económicos. Desarrollo Económico, 105, pp. 3-27, 1987.

ROBERTS, J. T. Subcontracting and the omitted social dimensions of large development projects: household survival at the Carajás mines in the Brazilian Amazon. Economic Development and Cultural Change, 43, pp. 735-758, 1995.

SANTOS, Rodrigo. Estado Nacional e desenvolvimento econômico na Amazônia Oriental: modelos de ação estatal e representações da modernização induzida nos últimos 40 anos. En Ramalho y Ferretti (orgs.), Amazônia: desenvolvimento, meio ambiente e diversidade sociocultural. São Luis: EdUFMA, 2009.

SANTOS, Valdeci. A economia do sudeste paraense: fronteira de expansão na periferia brasileira. Tese em Desenvolvimento Econômico, UNICAMP, 2011.

SEOANE, José et al. Extractivismo, despojo y crisis climática. Buenos Aires: Herramienta, 2013.

SMITH, John. Imperialism in the Twenty-First Century: Globalization, Super-Exploitation and Capitalism's Final Crisis. New York, NY: Monthly Review Press, 2016.

SOTELO VALENCIA, Adrián. The future of work: super-exploitation and social precariousness in the 21st Century. Leiden: Brill, 2016.

SOTELO VALENCIA, Adrián. Crítica a la crítica de Katz a Marini: ¿una teoría de la dependencia sin superexplotación? Mejor una teoría de la dependencia con superexplotación revisitada y actualizada. Disponível em: http://rebelion.org/docs/235669.pdf. (Acessado em 12 janeiro 2021). 2017.

STANDING, Guy. The precariat, London: Bloomsbury, 2011.

STAVENHAGEN, Rodolfo. Clases, colonialismo y aculturación. América Latina: Revista del Centro Latinoamericano de Investigaciones en Ciencias Sociales, Vol. VI (4), 1963.

STAVENHAGEN, Rodolfo. Siete Tesis Equivocadas Sobre América Latina [1965]. En Stavenhagen, Sociología y Subdesarrollo. México: Nuestro Tiempo, 1981.

STAVENHAGEN, Rodolfo. Seven erroneous theses 50 years later. Latin American Perspectives, vol.45 (2), 219, 2018. 
SVAMPA, M.; Antonelli, M. Minería transnacional, narrativas del desarrollo y resistencias sociales. Buenos Aires: Biblos, 2010.

VELHO, Otávio. Capitalismo autoritário e campesinato. Rio de Janeiro: Difel, 1976.

VELHO, Otavio. Frentes de expansão e estrutura agrária: estudo do processo de penetração numa área da Transamazônica. Rio de Janeiro: Zahar, 1972.

VELHO, Otavio. Análise preliminar de uma frente de expansão da sociedade brasileira [1967]. En Velho, Sociedade e agricultura. Rio de Janeiro: Zahar, 1982.

VELHO, Otavio. Campesinatos e política. Anuário Antropológico, 77, 1978.

VELHO, Otávio. O conceito de camponês e sua aplicação à análise do meio rural brasileiro [1969]. En Velho, Sociedade e agricultura. Rio de Janeiro: Zahar, 1982.

VELHO, Otavio. Revisitando as frentes de expansão. En Velho, Revisitando as frentes de expansão. Rio de Janeiro/São Luís: Ford Fundation/Casa 8, 2016. 